\title{
CONTROLE DO USO DE SACOLAS PLÁSTICAS E OS POSSÍVEIS BENEFÍCIOS AMBIENTAIS
}

\author{
Rossana Abud Cabrera-Rosa ${ }^{1}$
}

Flávia Alves Verza ${ }^{2}$

Casimiro Cabrera-Peralta ${ }^{3}$

RESUMO: O uso de sacolas plásticas para o acondicionamento/transporte de produtos consumidos representa item importante de conforto e praticidade nas atividades cotidianas. O descarte inadequado constitui risco para o meio ambiente. O objetivo deste estudo foi conhecer e quantificar o uso e as propostas de substituição das sacolas plásticas em supermercados e verificar se as sacolas biodegradáveis realmente apresentavam a degradação descrita pelo fabricante. Desta forma, foi aplicado questionário fechado nas empresas selecionadas. As questões solicitavam informações sobre número de sacolas/mês, impacto econômico/social da proibição do uso, nível de satisfação relatado ao supermercado pelos clientes, nível de insatisfação relatado ao supermercado pelos clientes, aumento ou não da venda de sacos de lixo, existência de atividades de educação/conscientização ambiental para com os funcionários e clientes. Através das visitas aos seis supermercados, foram obtidos dados necessários à pesquisa. Esses dados foram submetidos à tabulação para a visualização dos resultados. Para a avaliação do tempo de degradação, as sacolas foram enterradas em vasos com terra comum, deixados à temperatura ambiente, 186 dias, BIOFLORA UniSALESIANO. Os

\footnotetext{
${ }^{1}$ Professora Doutora e Coordenadora do Curso Ciências Biológicas - UniSALESIANO Araçatuba -SP rossana@salesiano-ata.br

${ }_{3}^{2}$ Acadêmica do Curso de Ciências Biológicas - UniSALESIANO Araçatuba - SP flaviaverza@hotmail.com

3 Professor Titular do Curso de Ciências Biológicas - UniSALESIANO Araçatuba - SP profcabreraperalta@gmail.com
} 
supermercados pesquisados demonstraram insatisfação dos clientes na retirada das sacolas plásticas, apenas um supermercado relatou que seus clientes não se manifestaram contra o uso de eco bags. Ao serem desenterradas, as sacolas plásticas não demonstraram degradação significativa $(<0,10)$, mesmo as biodegradáveis e as compostáveis. Através dos resultados obtidos, pôde-se observar a necessária formulação de alternativas eficientes para evitar o uso das sacolas plásticas, assim como a necessidade de realizar a adição de componentes que promovam a biodegradação das sacolas.

Palavras-chave: Sacolas Plásticas. Sacolas Biodegradáveis. Efeitos Ambientais.

Apoio: CNPq Processo 149374/2012-7

\section{INTRODUÇÃO}

O uso de sacolas plásticas para o acondicionamento e transporte de produtos consumidos pela população representa um item importante de conforto e praticidade nas atividades cotidianas. O plástico é um dos materiais mais encontrados nos aterros sanitários e, por esse motivo, constitui sério problema ambiental. Sua alta resistência proporciona danos ao meio ambiente, pois o plástico pode durar séculos sem sofrer decomposição. De sacolinhas de supermercados a utensílios de uso cotidiano, peças de automóveis, embalagens de produtos variados e garrafas PET, cerca de $20 \%$ do lixo doméstico é composto por plásticos [5].

Nos últimos anos, vários países em todo o mundo têm reconhecido a necessidade de reduzir a quantidade de materiais plásticos desperdiçados e descartados, além de incentivarem a reciclagem, que apesar de depender, em grande parte, da coleta e seleção do produto, e apesar de grande parte dos municípios brasileiros possuírem algum tipo de coleta seletiva, não atingem a totalidade de itens recicláveis [5]. 
Como consequência deste crescente uso de polímeros, em 1995, mais de 600 mil toneladas de lixo plástico industrial, urbano, rural, entre outros, foram geradas no Brasil e, só a cidade de São Paulo, produziu cerca de 12 mil toneladas por dia de lixo sólido, sendo que, 700 toneladas deste, corresponderam a embalagens plásticas [9].

O acelerado consumo e descarte de plásticos usados em aplicações como embalagens, está levando a um alarmante acúmulo nos depósitos de lixo de materiais que podem levar centenas de anos para se decompor $[4,6]$.

A falta de degradabilidade e os problemas de poluição levaram à preocupação em relação ao plástico [4]. Com o uso excessivo, a necessidade de plásticos biodegradáveis e biodegradação de resíduos de plástico têm assumido uma importância crescente nos últimos anos. A consciência do problema dos resíduos e seu impacto sobre o meio ambiente tem despertado novo interesse na área de polímeros biodegradáveis. $O$ interesse em questões ambientais está crescendo e há cada vez mais exigências para o desenvolvimento de material que não prejudique o meio ambiente de forma significativa [3].

Atualmente, observa-se preocupação voltada para o desenvolvimento e execução de atividades com base na educação ambiental voltada ao combate do desperdício e do descarte inadequado de plástico. A sociedade apresenta exigências crescentes sobre informações e alternativas que contribuam significativamente para a diminuição do impacto ambiental promovido pelo uso do plástico no planeta. Alguns polímeros, como termorrígidos e borrachas, não podem ser reciclados de forma direta, pois não existe uma forma de refundi-los ou despolimerizá-los. Na maioria das vezes a reciclagem de termoplásticos não é economicamente viável devido ao seu baixo preço e baixa densidade [7].

Os plásticos convencionais são produzidos, principalmente, a partir de matériasprimas provenientes do petróleo, um recurso natural não renovável. Inserido no contexto atual de preocupação crescente com o ambiente, tem-se o bioplástico [8], material produzido a partir de matéria-prima renovável e que, quando descartado em condições que favorecem o processo de decomposição do mesmo, integra-se mais rápido à natureza do que os plásticos convencionais [7]. 


\section{DESENVOLVIMENTO}

O presente trabalho é resultado de revisão bibliográfica visando à obtenção de informações a respeito da produção, das propriedades e das aplicações das sacolas plásticas, seu impacto ambiental e uma alternativa contra o desperdício do plástico, como o bioplástico.

O objetivo deste estudo foi conhecer e quantificar o uso e as propostas de substituição das sacolas plásticas em supermercados e verificar se as sacolas biodegradáveis realmente apresentavam a degradação descrita pelo fabricante.

Para atingir os objetivos desta pesquisa, foi organizado questionário fechado e o mesmo, aplicado nas empresas selecionadas. As questões solicitavam informações sobre número de sacolas utilizadas por mês, impacto econômico/social da proibição do uso das sacolas plásticas na empresa, nível de satisfação relatado ao supermercado pelos clientes, nível de insatisfação relatado ao supermercado pelos clientes, aumento ou não da venda de sacos de lixo, existência de atividades de educação/conscientização ambiental para com os funcionários e clientes da empresa. Através das visitas aos seis supermercados, foram obtidos os dados necessários à pesquisa. Esses dados foram submetidos à tabulação para a visualização dos resultados.

Foi realizado um levantamento bibliográfico com seleção e leitura dos artigos incluídos na pesquisa. Para a definição dos critérios de inclusão de artigos científicos foram utilizados dados referentes ao tema do artigo e utilizados aqueles que continham relação com os termos meio ambiente, sacolas plásticas, biodegradável, poluição e bioplástico. Os artigos utilizados foram de 1995 a 2011. Com a finalidade de preenchimento de formulário próprio para o levantamento de dados, foram visitadas seis empresas que estão participando ativamente do processo de controle do uso de sacos plásticos para o transporte de mercadorias. As empresas visitadas foram supermercados, empresas que são altamente representativas para o processo de obtenção de dados quantitativos diários, mensais e anuais do material poluente do meio ambiente. 


\section{Then

Para a obtenção dos dados referentes à utilização de sacolas plásticas pelos supermercados, foram investigados os seguintes itens:

1. o número de sacolas utilizadas por mês,

2. o impacto econômico e social da proibição do uso das sacolas plásticas,

3. o nível de satisfação relatado ao supermercado pelos clientes,

4. o nível de insatisfação relatado ao supermercado pelos clientes,

5. o aumento ou não aumento da venda de sacos plásticos de lixo,

6. a existência de atividades de educação e conscientização ambiental para com os funcionários da empresa,

7. a existência de atividades de educação e conscientização ambiental para com os clientes/consumidores da empresa.

Para efeito de comparação da degradação das sacolas plásticas utilizadas pelos supermercados pesquisados, foi confeccionado bioplástico em laboratório do UniSALESIANO Araçatuba, e o mesmo foi enterrado na BIOFLORA UniSALESIANO, também por 186 dias, nas mesmas condições climáticas.

O bioplástico foi confeccionado usando amido de milho como matéria-prima. Estes plásticos feitos de milho, batata, e outros vegetais estão conquistando um importante nicho no mercado mundial, diminuindo a dependência dos produtos derivados de petróleo. Para a confecção do Bioplástico, foram utilizados os materiais abaixo citados, seguindo as proporções descritas:

Material:

Amido de milho - 30g

Água destilada $-500 \mathrm{ml}$

Solução de HCL $1 \mathrm{M}-2,4 \mathrm{ml}$

$\mathrm{NaOH} 1 \mathrm{M}$

Glicerina - 24ml

Papel indicador de $\mathrm{pH}$

Equipamentos e vidrarias:

Agitador Magnético

Balança de Precisão

Becker 
Espátula

Proveta

Pipeta graduada

Pêra

Tripé

Bico de bunsen

Manta de amianto

Técnica de preparo:

1. Colocar o amido dentro do Becker

2. Adicionar água destilada

3. Manter sob agitação até a completa mistura dos elementos

4. Adicionar o HCL (ácido clorídrico)

5. Adicionar a Glicerina

6. Deixar ferver e, após fervura, manter sob aquecimento brando por 15min

7. Retirar do fogo e adicionar $\mathrm{o} \mathrm{NaOH}$

8. Verificar $\mathrm{opH}$, com o papel indicador de $\mathrm{pH}$

9. Derramar o bioplástico sobre superfície lisa, limpa e plana e deixar secar por 24 horas.

Para a avaliação do tempo de degradação das sacolas plásticas, as mesmas foram enterradas em vasos com terra comum, deixados à temperatura ambiente por 186 dias, na BIOFLORA UniSALESIANO.

Para efeito de comparação em relação ao tempo de degradação, duas amostras de bioplástico confeccionado no laboratório da faculdade foram enterradas nas mesmas condições das sacolinhas plásticas. Com quinze dias a primeira amostra foi desenterrada e com trinta dias a segunda amostra de bioplástico foi desenterrada.

Os resultados obtidos referentes à degradação das sacolas plásticas demonstram que todas as sacolas utilizadas pelos supermercados pesquisados não sofreram degradação significativa. Apenas uma das sacolas utilizadas demonstrou início de 
decomposição, mas esta não atingiu nem $10 \%$ da totalidade da sacola (Figuras 1, 2, 3, 4, $5,6$ e 7$)$.

Figuras 1 a 7 - Sacolas plásticas utilizadas e desenterradas após 186 dias de exposição ao sol e à chuva, em temperatura ambiente, no período dos meses de junho e julho, BIOFLORA UniSALESIANO.

Figura 1 e 2

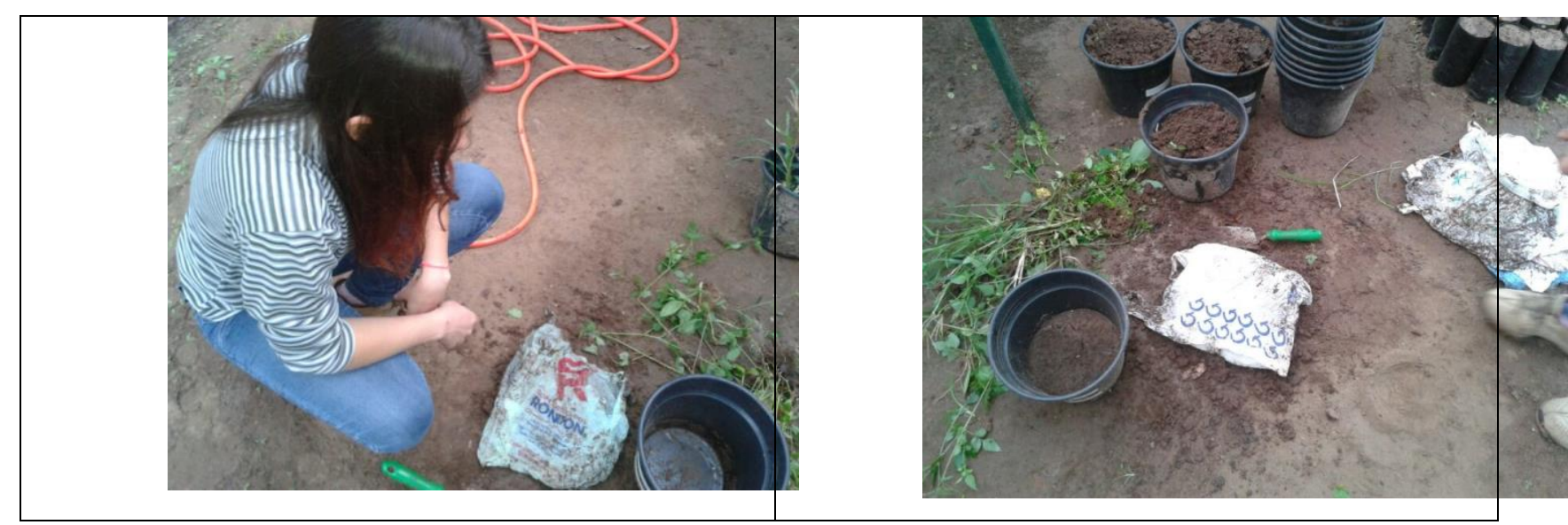

Figura 3 e 4

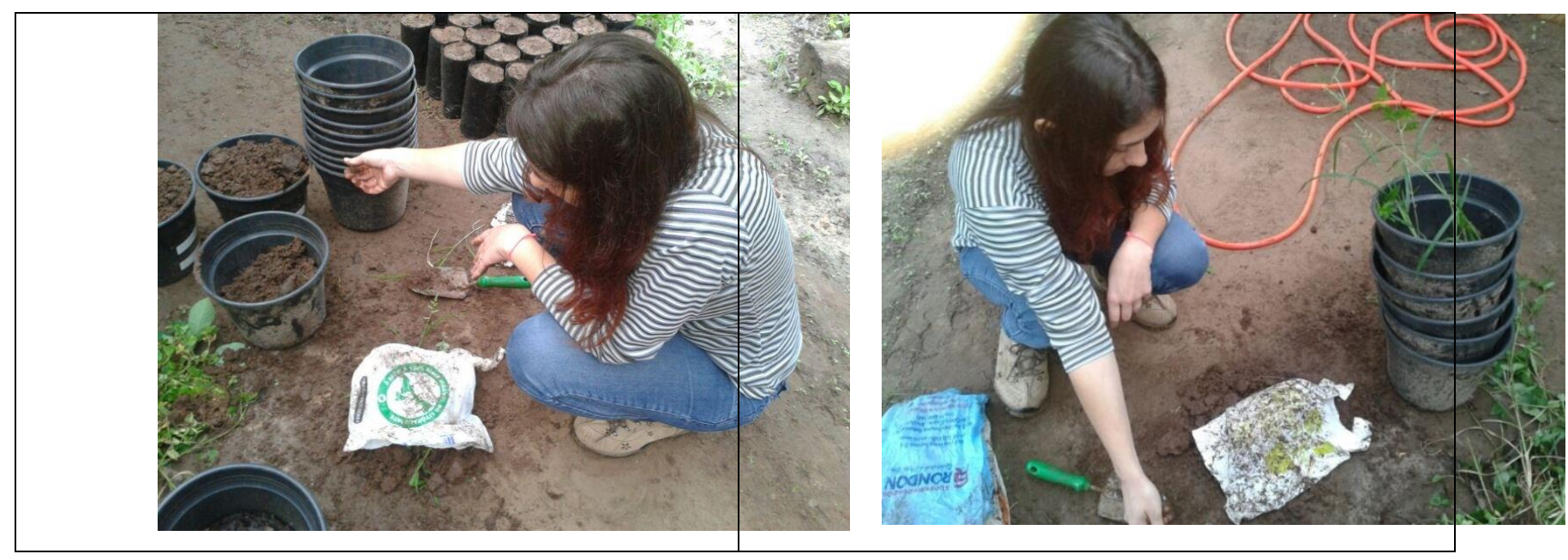


Figura 5 - 6

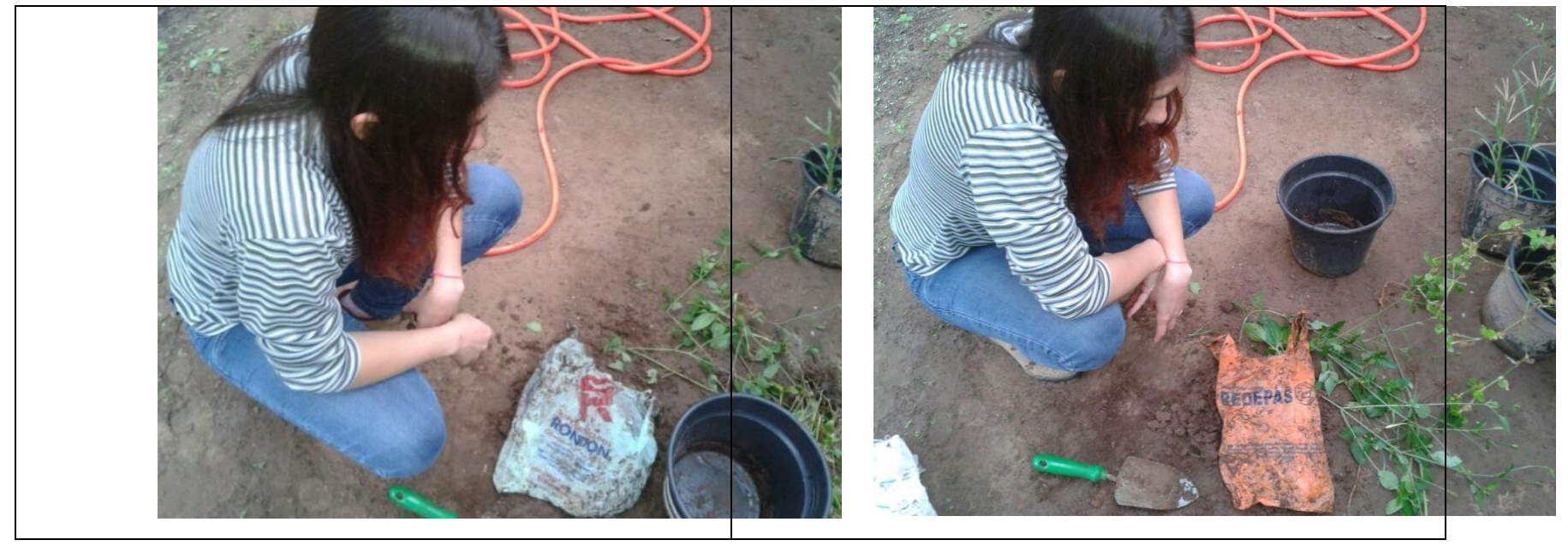

Figura 7 - 8

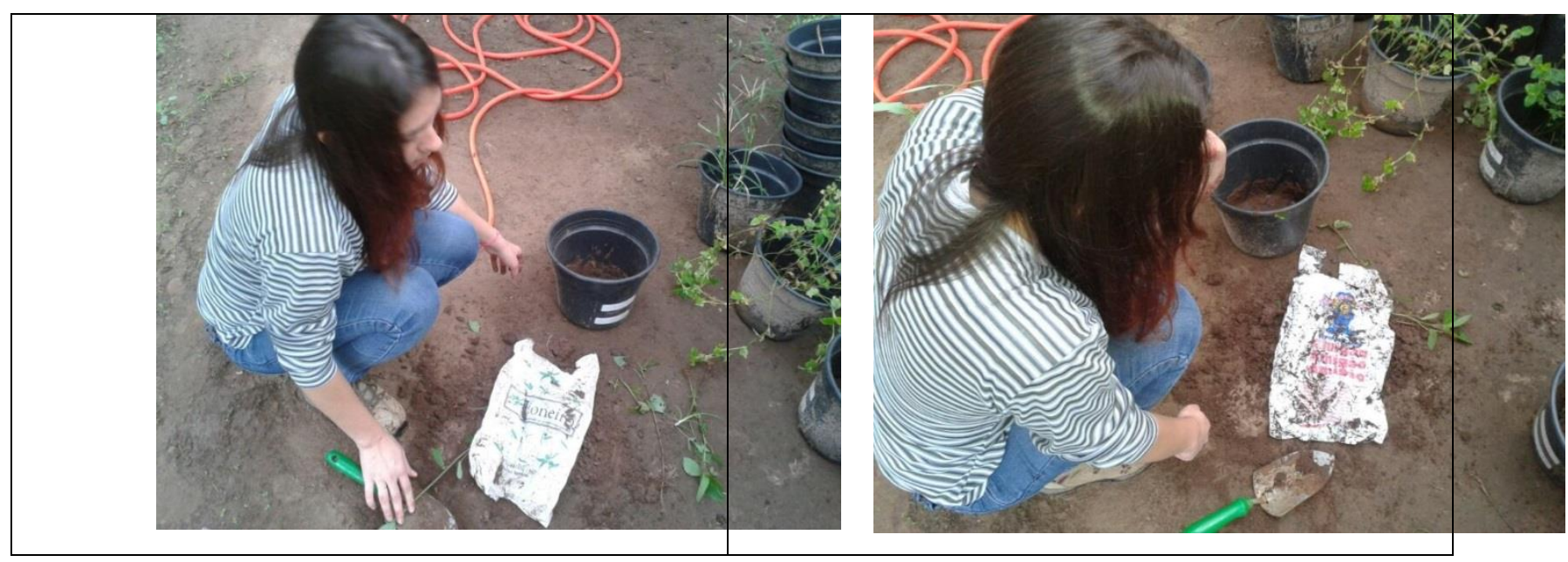


Figura 9 - 10

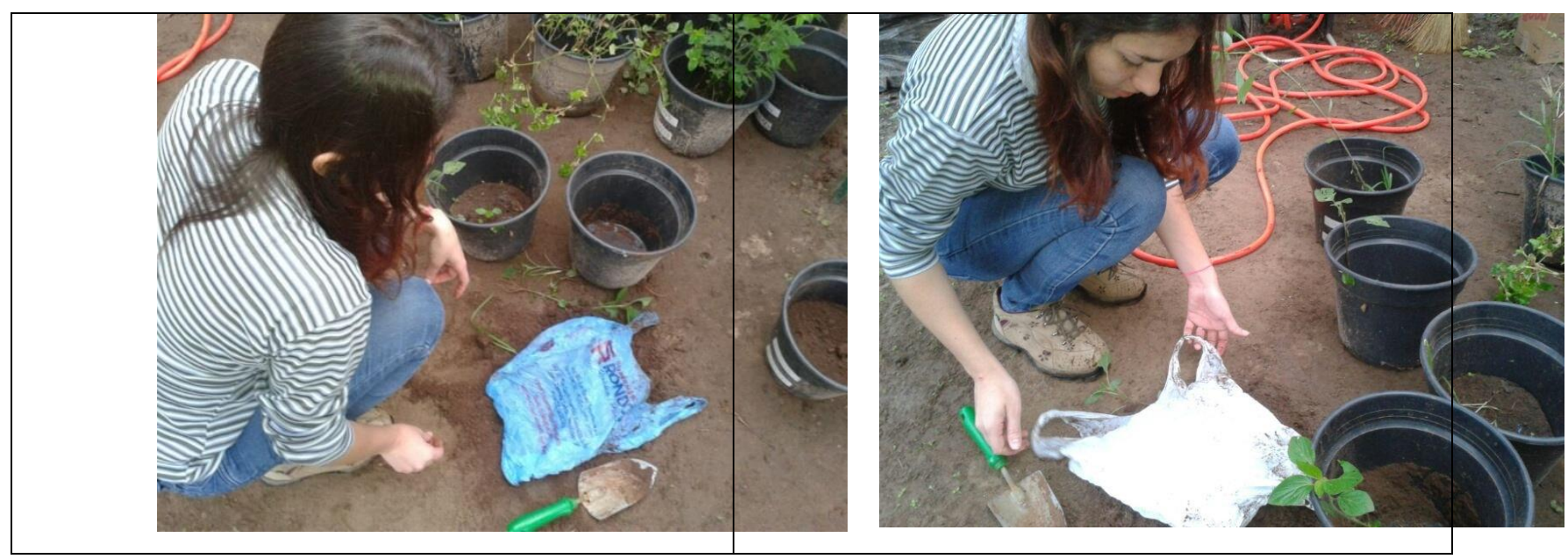

Figura 11 e 12

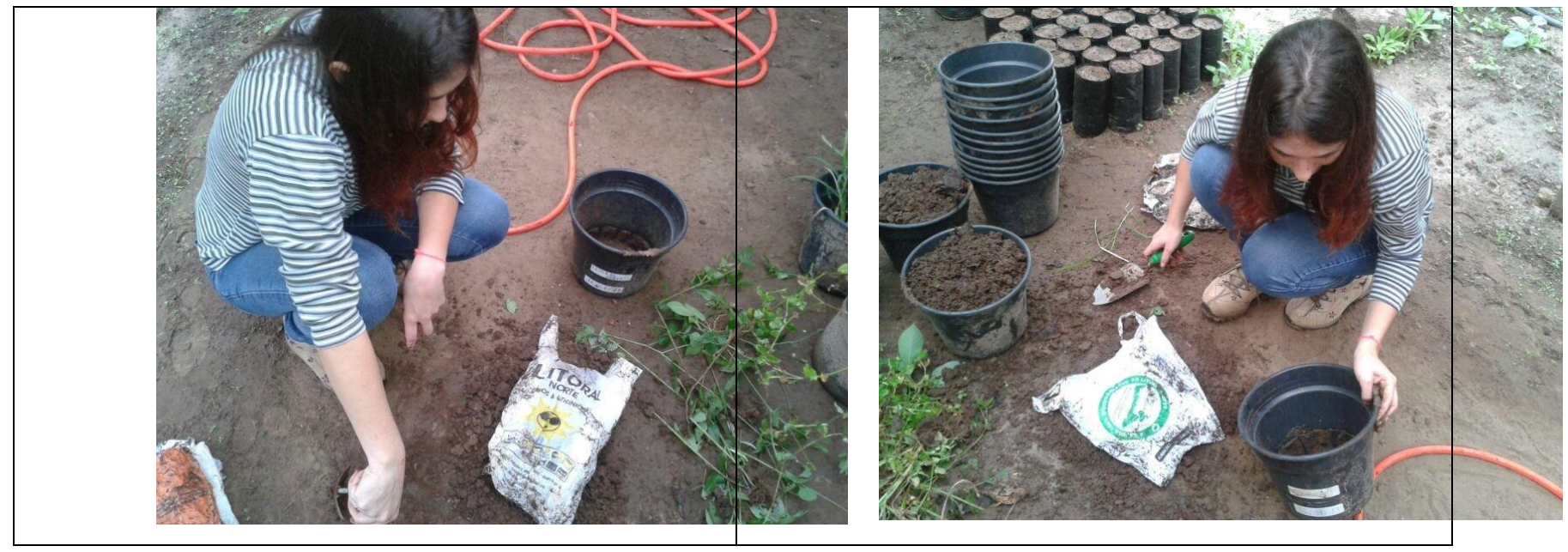


Figura 13

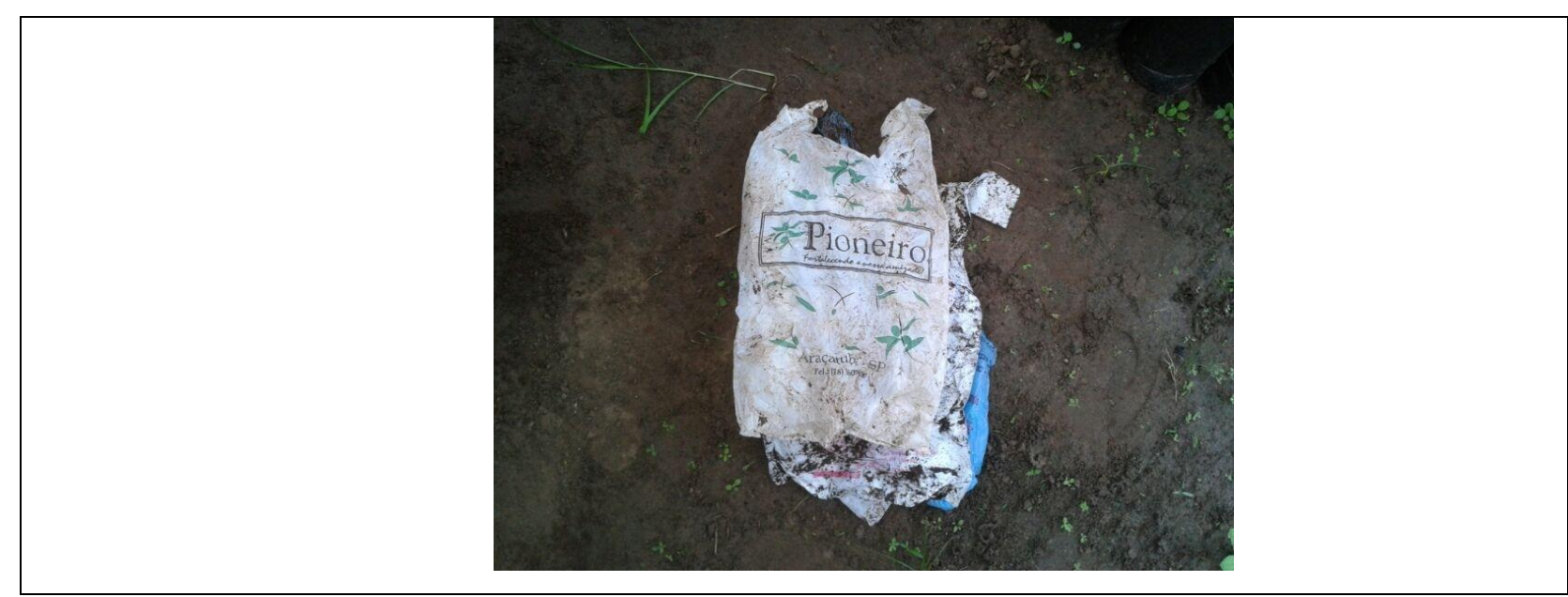

Em relação ao grau de insatisfação dos clientes quanto à restrição do uso de sacolas plásticas para o transporte de alimentos, os resultados mostraram que a maioria dos supermercados pesquisados, registraram insatisfação dos clientes na retirada das sacolas plásticas. Apenas um supermercado relatou que seus clientes não se manifestaram contra a substituição das sacolas por eco bags. Este, por sua vez, executa a educação ambiental no dia a dia, incentivando o uso de alternativas para o transporte de mercadorias, mesmo antes da retirada obrigatória das sacolas plásticas.

O número de sacolas plásticas utilizadas por cada estabelecimento comercial pesquisado variou significativamente, mas esta variação está relacionada com o porte do supermercado, além do grau de conhecimento sobre a consciência ambiental dos clientes (Gráfico 1). 


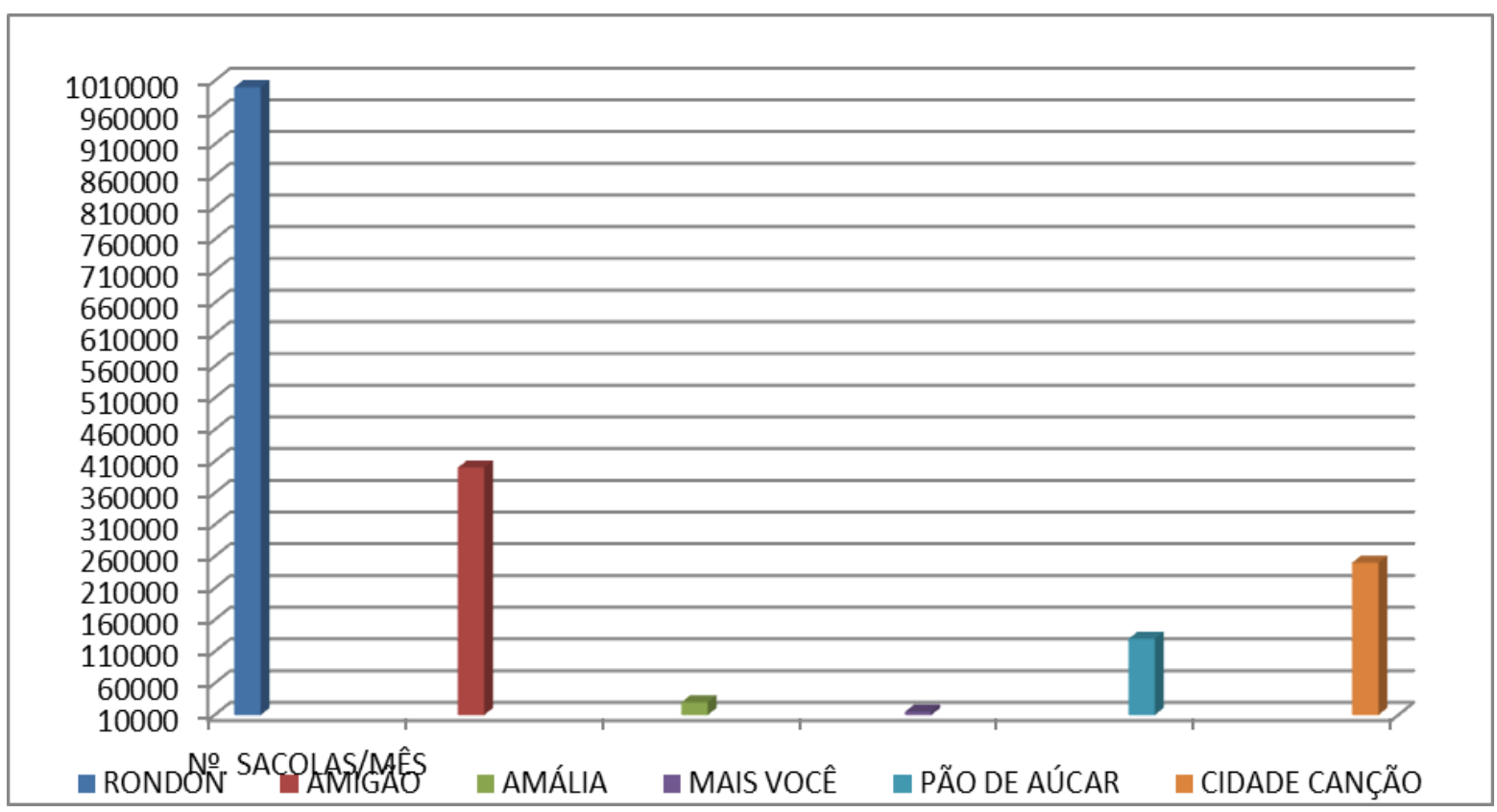

Gráfico 1 - Número de Sacolas plásticas utilizadas por cada estabelecimento comercial por mês.

Os clientes que demonstraram menor grau de insatisfação foram aqueles que frequentavam o estabelecimento que pratica a educação ambiental como rotina.

Os supermercados/mercados visitados totalizaram seis estabelecimentos, sendo que quatro foram descritos pelo próprio gerente como sendo de grande porte, um foi descrito como de médio porte e outro de pequeno porte (Gráfico 2).

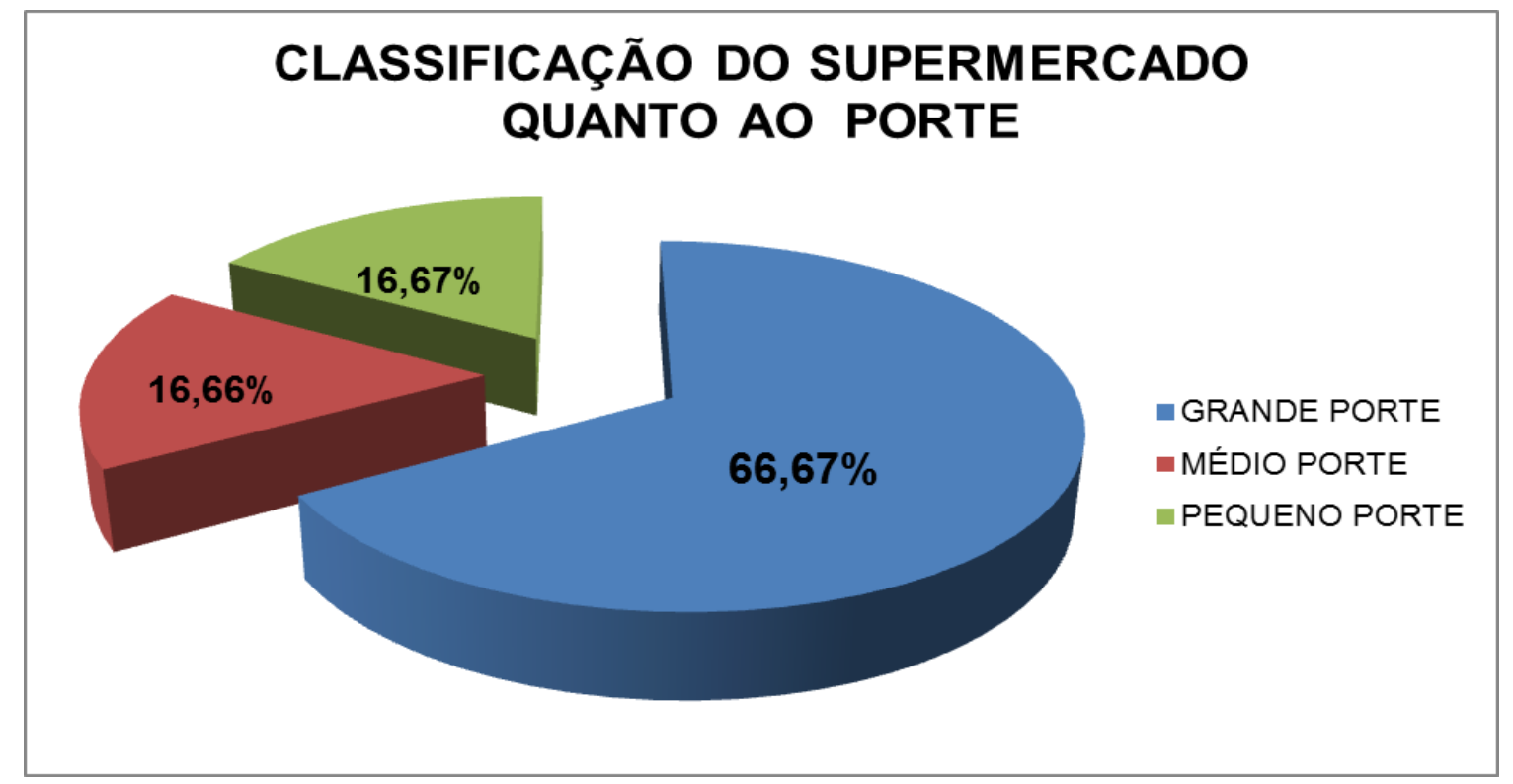


Gráfico 2 - Descrição do porte dos estabelecimentos comerciais visitados, de acordo com o volume de vendas e frequentadores de cada local.

Os dados relativos aos estabelecimentos comerciais seguem abaixo descritos:

1) Supermercado Rondon

O Supermercado Rondon é o maior de Araçatuba, possui duas lojas e uma terceira em construção e sua clientela abrange toda a região. A disponibilização de sacolas para os consumidores é muito alta grande, devido ao porte do supermercado grande porte. O supermercado encomenda cerca de um milhão de sacolas plásticas por mês em cada loja da empresa ATP Indústria e Comércio de Plásticos Ltda., localizada na cidade de São Paulo/SP. Assim, acaba atingindo um número de dois milhões de sacolas plásticas/mês. Porém o supermercado apoia o consumo consciente e reutiliza todo o seu material plástico e de papel prensando e reciclando em empresas do ramo, na cidade de Araçatuba. Através de folders e panfletos, o supermercado buscou orientar seus clientes em relação à proibição das sacolinhas. A maioria das pessoas não se manifestou negativamente em relação à proibição das sacolas plásticas, pois o supermercado tem como objetivo atender seus clientes da melhor forma possível, assim disponibilizavam caixas de papelão e sacos plásticos antes descartados. Sacolas Ecológicas foram disponibilizadas para venda, e o consumo de sacos de lixo subiu cerca de vinte por cento, o que não foi considerado um aumento significativo, pois não há como suprir a quantidade de sacolas plásticas, trocando as mesmas por sacos de lixo. Todos os funcionários passam por treinamento ao serem contratados e a cada quatro meses esse treinamento é reforçado. São ensinados a utilizar as sacolinhas sem desperdício, porém alguns consumidores exigem a colocação de poucos produtos por sacola ou mais de uma sacola por produto, o que acaba provocando um consumo desnecessário de sacolas.

\section{2) Supermercado Amigão}

O supermercado Amigão é uma das lojas âncora do Hiper Center Araçatuba, um conglomerado de lojas com supermercado, praça de alimentação e agência bancária. Sua disponibilização mensal é de trezentas a quatrocentas mil sacolas plásticas, encomendadas de uma empresa de São Paulo. Ao surgir a proposta de conscientização com a proibição das sacolas plásticas, o supermercado recebeu muitas reclamações, pois 
a disponibilização de outros tipos de materiais para armazenamento parcial de produtos como caixas de papelão ou sacos foi pouca em relação à grande quantidade de clientes. Os mesmos argumentaram reutilizar as sacolas para o descarte do lixo. O supermercado orienta seus funcionários a terem controle mínimo na utilização das sacolas, e ainda hoje esse controle é utilizado. O consumo de sacos de lixo não sofreu alteração na época em que a proposta entrou em vigor, porém o supermercado disponibilizou para venda as sacolas ecologicamente corretas, que foram utilizadas pelos clientes, mas com o retorno das sacolas plásticas o consumo consciente voltou a ser esquecido.

3) Supermercado Amália

O Supermercado Amália é de médio porte, possui um consumo de sacolas plásticas de vinte a trinta mil mensais. Seu material descartável é reutilizado por uma empresa que realiza coleta seletiva. Quando a proposta de proibição das sacolas plásticas estava em andamento, o supermercado orientou seus clientes através dos funcionários, e ainda hoje, os mesmos realizam medidas de controle diminuindo quantidades desnecessárias. A retirada das sacolas plásticas foi mal recebida pelos clientes, que mesmo utilizando caixas de papelão disponibilizadas pelo supermercado reclamavam muito pela falta de conforto e praticidade. Com o retorno das sacolas plásticas, o supermercado percebeu, no início, uma conscientização por parte de alguns clientes, mas depois de algum tempo, o consumo voltou ao normal.

\section{4) Mais Você}

O Supermercado Mais Você está presente em Araçatuba há onze anos, é um mercado de pequeno porte com disponibilização de sacolas de aproximadamente quinze mil mensais. Por ser de pequeno porte houve pouca orientação aos clientes, e nenhuma medida de controle. O mercado não reutiliza seu material descartável. O consumo de sacos de lixo continuou normal depois da proposta de retiradas de sacolas plásticas acontecer, houve venda de sacolas ecologicamente corretas, mas os clientes não aceitaram positivamente essa proposta, porém não houve muita manifestação a respeito. 
5) Supermercado Pão de Açúcar

O Supermercado Pão de Açúcar apoia o consumo consciente, através de ações educacionais, desde sua chegada á Araçatuba, cerca de trinta anos atrás. Suas sacolas vêm da matriz em São Paulo, cerca de cento e trinta mil mensais. O supermercado conta com uma estação de reciclagem dentro da loja, e além de reutilizar seu material descartável ainda incentiva seus clientes ao consumo consciente. Não foi notada alteração na utilização de sacolas com a medida de prevenção, e também não houve reclamação por parte dos clientes, pois na sua maioria são conscientes já que o supermercado apoia a redução e reutilização. Através de medidas de controle e orientação, os funcionários auxiliam seus clientes no uso mais correto das sacolas plásticas. O Supermercado conta ainda com a venda de sacolas ecologicamente corretas e apoia sua utilização. Medidas preventivas sempre são tomadas em prol ao meio ambiente, o que torna os clientes uma minoria que aprova essa prática de conscientização em minimizar os impactos ambientais promovidos pela utilização desnecessária e descarte incorreto de sacolas plásticas.

\section{6) Cidade Canção}

O Supermercado Cidade Canção está presente há pouco tempo em Araçatuba, porém possui utilização mensal de aproximadamente duzentas e cinquenta mil sacolas plásticas.

Seus clientes não aprovaram a proposta de retirada das sacolas plásticas, pois os mesmos esperam comodidade, o que fez o supermercado ficar em uma posição desconfortável já que alguns clientes reclamavam da venda de sacolas ecologicamente corretas. Não foi notado aumento na utilização de sacos de lixo. O descarte de material feito pela empresa é reciclado e mandado para Maringá - SP onde é vendido para empresas de reciclagem. Foi um alívio ao Supermercado o retorno de sacolas plásticas, porém sua utilização continuou a mesma de antes da proposta de redução, mesmo o supermercado disponibilizando panfletos e folders sobre o consumo consciente [1, 2].

Ao serem desenterradas, as sacolas plásticas não demonstraram degradação significativa $(<0,10)$, mesmo as biodegradáveis e as compostáveis. O bioplástico, após quinze dias, demonstrou degradação parcial e, após trinta dias, total degradação. 


\section{CONCLUSÕES}

Através dos resultados obtidos, pode-se concluir que é necessária a formulação de alternativas eficientes para evitar o uso das sacolas plásticas, assim como há a necessidade de realizar a adição de componentes que promovam a biodegradação das sacolas. Para o consumidor brasileiro consciente, a opção de diminuir o consumo de sacos plásticos é interessante e muito bem aceita. O plástico seja ele comum, verde, oxibiodegradável ou biodegradável demostrou ser, nesta pesquisa, um problema ambiental relevante, que solicita a realização de novos estudos e a adoção de medidas eficientes para a contenção de seu consumo. Qualquer que seja o plástico utilizado haverá prejuízos ao meio ambiente e às cidades.

Ainda, conclui-se que o uso racional dos sacos plásticos e o correto destino dado à ele, como a reciclagem são as opções confiáveis, porém, a inclusão do bioplástico no mercado poderia amenizar o problema no meio ambiente, devido à sua eficiência de degradação.

\section{REFERÊNCIAS}

FABRO, A. T., LINDEMANN, C., VIEIRA, S. C. Utilização de sacolas plásticas em supermercados. Rev. Ciências do Ambiente On-Line, v. 3, n. 1, 2007.

GONÇALVES-DIAS, S. L. F. Há vida após a morte: um (re)pensar estratégico para o fim da vida das embalagens. Gestão \& Produção, v.13, n.3, p.463-474, set.-dez. 2006.

GORNI, A. A. Aproveitamento de Plástico Pós-Consumo na Forma de Combustível Para Altos-Fornos e Coquerias. Trabalho apresentado no PlastShow 2004, Aranda Eventos, São Paulo SP, 27 a 29 de Abril de 2004. 
MUCELIN, C. A., BELLINI, M. Lixo e impactos ambientais perceptíveis no ecossistema Urbano. Sociedade \& Natureza, Uberlândia, 20 (1): 111-124, jun. 2008.

RÓZ, A. L. O Futuro dos Plásticos: Biodegradáveis e Fotodegradáveis. Polímeros: Ciência e Tecnologia. 2003.

SANTOS, A. S. F., AGNELLI, J. A. M., MANRICH, S. Tendências e Desafios da reciclagem de Embalagens Plásticas. Polímeros: Ciência e Tecnologia, vol. 14, n 5, p. 307-312, 2004.

SHAH, A. A., HASAN, F., HAMEED, A., AHMED, S. Biological degradation of plastics: A comprehensive review. Biotechnology Advances. 2008.

TELLES, M.R.; SARAN, L.M.; UNÊDA-TREVISOLLI, S.H. Produção, propriedades e aplicações de bioplástico obtido a partir da cana-de-açúcar. Ciência \& Tecnologia: FATEC-JB, Jaboticabal. 2011.

WIEBECK H., PIVA, A.N., RISSO, W.M., ANGELATAKIS, A.R., SCHWARZ, L.B., SOARES, M.A. Dificuldades na reciclagem do plástico do resíduo sólido urbano do lixão. Anais do 3ํㅡㄹ Congresso Brasileiro de Polímeros. 1995. 